\title{
Cationic Copolymerization of Tetrahydrofuran with $\varepsilon$-Caprolactone
}

\author{
Yuya Yamashita, Koichi Ito, Kazumasa Chiba, \\ and Shigeyuki Kozawa \\ Department of Synthetic Chemistry, Faculty of Engineering, \\ Nagoya University, Nagoya, Japan.
}

(Received October 12, 1971)

\begin{abstract}
Cationic copolymerization of tetrahydrofuran (THF) with $\varepsilon$-caprolactone $(\mathrm{CL})$ was carried out with some stable cationic salts. Both monomers are consumed simultaneously, but THF seems twice as reactive as CL, reflecting the high basicity of THF. The copolymerization system seems almost living in nature at higher THF feed and a copolymer of $\bar{M}_{n} 89000$ containing $13.9 \%$ of CL was obtained. However, fractionation of the product showed a broad distribution of the copolymer composition. The lower-molecular-weight fraction contained a higher proportion of CL. The X-ray diffraction pattern and differential scanning calorimeter thermogram showed the existence of the crystalline region of poly-THF and poly-CL. Thus the copolymerization may have proceeded by a two-state mechanism yielding a block copolymer.
\end{abstract}

KEY WORDS Cationic Copolymerization / Tetrahydrofuran / $\varepsilon$ Caprolactone /

Cationic polymerization of tetrahydrofuran (THF) has been studied extensively and the living nature of the system has been well established. ${ }^{1} \quad$ While the cationic polymerization of epoxides and oxetanes is suggested to proceed through the similar oxonium ion as the propagating species, chain transfer or termination reaction occurs significantly and copolymerization with THF was shown to deviate from the living system. ${ }^{1-3}$ Since the cationic polymerization of $\varepsilon$-caprolactone $(\mathrm{CL})$ has been shown to have some similarity with that of $\mathrm{THF}^{4,5}$ the copolymerization behavior of THF and CL was studied.

\section{EXPERIMENTAL}

\section{Reagents}

Commercial monomers and solvents were purified by the usual procedures, and dried over calcium hydride overnight in a vacuum system and distilled.

Triethyloxonium tetrafluoroborate $\left(\mathrm{Et}_{3} \mathrm{O} \cdot \mathrm{BF}_{4}\right)$ was prepared as described by Meerwein. ${ }^{6}$ 2Methyl-1,3-dioxolenium perchlorate $\left[\mathrm{CH}_{3} \mathrm{C}^{+} \mathrm{O}_{2-}\right.$ $\left.\left(\mathrm{CH}_{2}\right)_{2} \cdot \mathrm{ClO}_{4}^{-}\right](\mathrm{MDO})$ and $2,2^{\prime}$-octamethylenebis1,3-dioxolenium perchlorate $\left[\left(\mathrm{CH}_{2}\right)_{4} \mathrm{C}^{+} \mathrm{O}_{2}\left(\mathrm{CH}_{2}\right)_{2}\right.$.
$\left.\mathrm{ClO}_{4}^{-}\right]_{2}(\mathrm{OMDO})$ were prepared as described in a previous paper. ${ }^{7}$

\section{Polymerization Procedure}

Kinetic experiments were carried out in an ampoule under nitrogen. The monomer consumption was determined using a Hitachi KGL2B gaschromatograph with a Silicone D.C. packed column at $170^{\circ} \mathrm{C}$, by adding $o$-dichlorobenzene as an internal standard after termination with pyridine. Preparative experiments were carried out in a high vacuum system with the catalysts also prepared in vacuo. The reaction mixture was poured in methanol or water, and also the crude polymer was reprecipitated and freeze-dried.

\section{Characterization}

Number-average molecular weights were measured by a Hewlett-Packard 502 High Speed Membrane Osmometer or by a Hitachi 115 Vapor Pressure Osmometer in benzene solution. IR spectra were recorded on a Japan Spectroscopic Infrared Spectrophotometer IR-S with polymer films. NMR spectra in chloroform at $60^{\circ} \mathrm{C}$ were recorded on a Japan Electron Optics Spectrometer C-60. Gel-permeation chromatograms were measured in tetrahydro- 
furan solution by a Waters Model 200. Differential scanning calorimetry was conducted using a Perkin-Elmer Model 1B. X-ray diffraction was measured with polymer films with a Norelco X-ray diffractometer.

The copolymer composition was determined from NMR spectra in the case of high $\mathrm{CL}$ content and from IR spectra by using the relative optical density ratios at $1745 \mathrm{~cm}^{-1}$ of $\mathrm{CL}$ and at $1110 \mathrm{~cm}^{-1}$ of THF in case of low $\mathrm{CL}$ content.

\section{RESULTS AND DISCUSSION}

\section{Cationic Polymerization of $\varepsilon$-Caprolactone}

Bulk polymerization of $\mathrm{CL}$ with Lewis acids such as $\mathrm{SnCl}_{4}$ or $\mathrm{BF}_{3} \mathrm{Et}_{2} \mathrm{O}$ proceeds easily to high conversion at room temperature. ${ }^{4,5}$ The poly-CL is a crystalline powder, melting at temperatures between $53^{\circ}$ and $57^{\circ} \mathrm{C}$, and it is insoluble in methanol and ether, and soluble in chloroform and benzene. The molecular weight of the copolymer is relatively low in these cationic systems. The results of terminal group analysis of the polymer showed the existence of some double bonds and carboxylic groups. The occurrence of the transfer reaction was therefore suggested ${ }^{4}$. Because some complex reaction forming oligomers was observed at the initial stage with these catalyst systems, solution polymerization with stable cationic salts was carried out.

The results of the polymerization are shown in Figure 1. Although the increase of molecular weight with conversion shows the living nature of the polymerization, the deviation from the calculated value assuming the formation of a living polymer shows the occurrence of some transfer or termination reactions. Perchlorate anion as a counter anion seems more effective in suppressing the transfer or termination reactions at low conversion than tetrafluoroborate anion.

To clarify the propagating species of the polymerization, the reaction mixture of equimolar amounts of triethyloxonium tetrafluoroborate and $\mathrm{CL}$ in ethylene dichloride was kept for 48 $\mathrm{hr}$ at room temperature and then poured into excess methanol, concentrated and placed

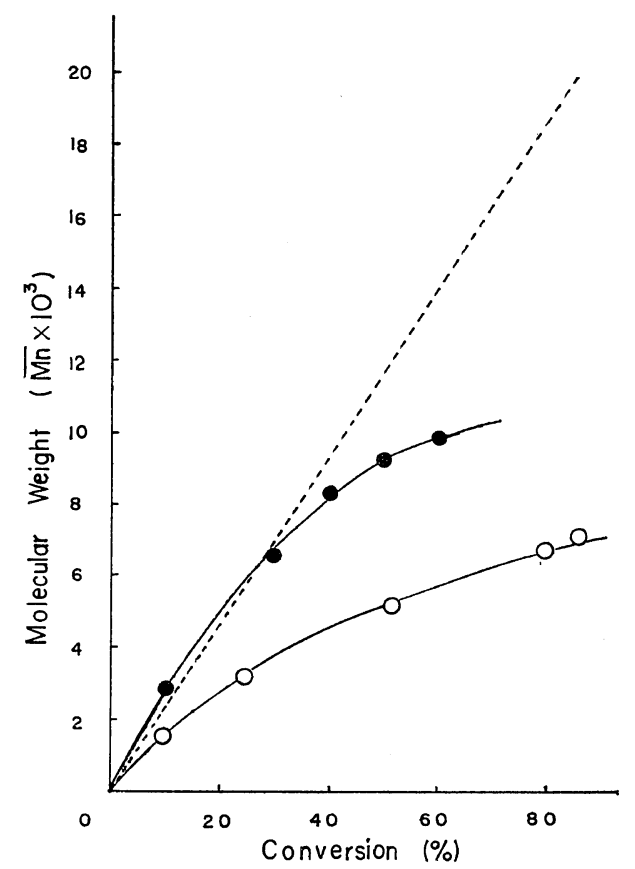

Figure 1. Molecular weight increase in the homopolymerization of $\varepsilon$-caprolactone: $,[C L]_{0}, 4.07$ $\mathrm{mol} / l,\left[\mathrm{CH}_{3} \mathrm{CO}_{3}\left(\mathrm{CH}_{2}\right)_{2} \mathrm{ClO}_{4}\right]_{0}, 2.72 \times 10^{-2} \mathrm{~mol} / l$, at $20^{\circ} \mathrm{C}$ in $\mathrm{CH}_{3} \mathrm{NO}_{2} ; \bigcirc,[\mathrm{CL}]_{0}, 434 \mathrm{~mol} / l,\left[\mathrm{Et}_{3} \mathrm{O} \cdot \mathrm{BF}_{4}\right]_{0}$, $2.88 \times 10^{-2} \mathrm{~mol} / l$, at $30^{\circ} \mathrm{C}$ in $\left(\mathrm{CH}_{2} \mathrm{Cl}\right)_{2}$.

in the gaschromatograph. The main products were $\mathrm{CH}_{3} \mathrm{O}\left(\mathrm{CH}_{2}\right)_{5} \mathrm{COOCH}_{3}$ (A), $\mathrm{C}_{2} \mathrm{H}_{5} \mathrm{O}\left(\mathrm{CH}_{2}\right)_{5}$ $\mathrm{COOCH}_{3}$ (B), and $\mathrm{C}_{2} \mathrm{H}_{5} \mathrm{O}\left(\mathrm{CH}_{2}\right)_{5} \mathrm{COOC}_{2} \mathrm{H}_{5}$ (C). The formation of $\mathrm{B}$ as the principal component is explained from the initiation by ethyl cation and termination by methoxy anion. The compounds $\mathrm{A}$ and $\mathrm{C}$ might have resulted from the decomposition of the initial oligomeric products. The formation of $\mathrm{B}$ agrees with our previous results obtained from NMR studies of the initiation reaction of the polymerization of lactones by triethyloxonium tetrafluoroborate. ${ }^{8}$ The propagating species of the cationic polymerization of lactones has been presumed as an oxonium ion from the copolymerization experiments of lactones with cyclic ethers ${ }^{11,13}$ and cyclic formals. $^{8}$ Thus, the propagation reaction is considered to involve the nucleophilic attack of ether oxygen on $\alpha$-carbonyl group of the oxonium ion as follows. 


$$
\begin{aligned}
& -\mathrm{O}\left(\mathrm{CH}_{2}\right)_{5} \mathrm{CO}-\stackrel{+}{\mathrm{O}} \underset{-\left(\mathrm{CO}_{2}\right)_{5}}{-\mathrm{CO}^{\prime}}+0^{\prime\left(\mathrm{CH}_{2}\right)_{5}} \rightarrow \rightarrow \\
& -\left[0\left(\mathrm{CH}_{2}\right)_{5} \mathrm{CO}_{2}-\stackrel{+}{-\left(\mathrm{CH}_{2}\right)_{5}}\right)
\end{aligned}
$$

Cationic Copolymerization of Tetrahydrofuran with $\varepsilon$-Caprolactone with Stable Cationic Salts

Copolymerization ef THF with CL was carried out with triethyloxonium tetrafluoroborate or with certain dioxolenium salts in bulk at $30^{\circ} \mathrm{C}$. The results given in Table I, show the slow formation of fairly high-molecular-weight copolymer containing considerable amounts of both components. The copolymer is a white rubbery mass soluble in ethyl ether and ethyl acetate, in which poly-CL is insoluble. Thus the formation of an apparently random copolymer might be suggested. Simultaneous consumption of both monomers during polymerization was observed by gas chromatography as shown in Figure 2. The copolymerization experiments with various feed ratios are shown in Table II. These results indicate that THF is a little more reactive than $\mathrm{CL}$, and that incorporation of $\mathrm{CL}$ decreases the molecular weight of copolymers. Although we can not determine the true monomer reactivity ratios for reasons that will be mentioned in the following section, the apparent monomer reactivity ratio can be estimated by the integrated equation of Mayo and Lewis as $r_{1}(\mathrm{THF})=0.7, r_{2}(\mathrm{CL})$ $=0.3$. According to the viewpoint that the relative reactively in cationic copolymerization depends upon the basicity of the monomer, ${ }^{9}$ this trend seems quite reasonable. The basicity values $\mathrm{pK}_{\mathrm{b}}{ }^{8}$ of monomers were measured as
THF (5.00), CL (5.31), 3,3-bischloromethyl oxetane (BCMO) (5.65), and the relative reactivity of monomers decreases in this order.

The analysis of the microstructure is necessary to confirm the randomness of the copolymer formed by ionic catalyst. The formation of the copolymer between lactones and cyclic ethers was studied for the case of $\beta^{11}$ - and $\gamma^{13}$ lactones, and an additional experiment for the case of $\varepsilon$-lactones is shown below. The monomer reactivity ratios of $\mathrm{BCMO}-\mathrm{CL}$ copolymerization system ${ }^{10}$ were reported as $r_{1}(\mathrm{BCMO})=$ $0.24, r_{2}(\mathrm{CL})=0.44$. In this system, randomness of the copolymer can be directly checked by NMR. The NMR spectrum in Figure 3 can be easily analyzed from our previous result on BCMO $-\beta$-propiolactone system. ${ }^{11}$

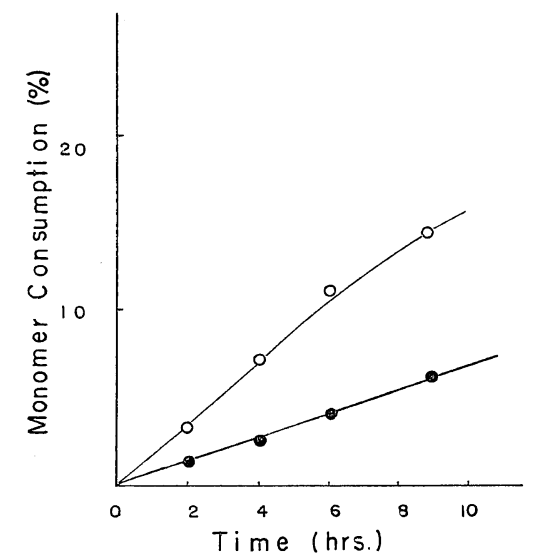

Figure 2. Monomer consumption in the copolymerization of tetrahydrofuran with $\varepsilon$-caprolactone: $\left.[\mathrm{THF}]_{0}, 5.40 \mathrm{~mol} / l ;[\mathrm{CL}]_{0}, 4.06 \mathrm{~mol} / l ;\left[\mathrm{Et}_{3} \mathrm{O} \mathrm{BF}\right]_{4}\right]_{0}$, $9.20 \times 10^{-2} \mathrm{~mol} / l$; at $30^{\circ} \mathrm{C}$ in $\left(\mathrm{CH}_{2} \mathrm{Cl}\right)_{2} ; \bigcirc$, THF; -, $\mathrm{CL}$.

Table I. Copolymerization of tetrahydrofuran with $\varepsilon$-caprolactone in a high vacuum system

\begin{tabular}{lcccc}
\hline \multicolumn{1}{c}{ No. } & 1 & \multicolumn{1}{c}{3} & \multicolumn{1}{c}{4} \\
\hline$[\mathrm{THF}]_{0}, \mathrm{~mol} / l$ & 9.13 & 6.18 & 9.67 & 9.67 \\
{$[\mathrm{CL}]_{0}, \mathrm{~mol} / l$} & 1.42 & 3.81 & 1.73 & 1.73 \\
Inhibitor & $\mathrm{Et}_{3} \mathrm{O} \cdot \mathrm{BF}_{4}$ & $\mathrm{Et}_{3} \mathrm{O} \cdot \mathrm{BF}_{4}$ & $\mathrm{OMDO}^{\mathrm{a}}$ & $\mathrm{OMDO}^{\mathrm{a}}$ \\
{[]$_{0}, 10^{-3} \mathrm{~mol} / l$} & 3.84 & 3.31 & 4.70 & 4.70 \\
Time & $10 \mathrm{day}$ & $12 \mathrm{day}$ & $56 \mathrm{hr}$ & $99 \mathrm{hr}$ \\
Yield, wt $\%$ & 32.7 & 11.2 & 11.0 & 16.7 \\
$\bar{M}_{n}$ (obsd) & 89000 & 36000 & 30000 & 36000 \\
$\bar{M}_{n}$ (calcd) & 70000 & 28000 & 23000 & 32000 \\
$\mathrm{CL}$ content, mol $\%$ & 13.9 & 24.3 & 15.6 & 15.3 \\
\hline
\end{tabular}

a 2,2'-octamethylene-bis-1,3-dioxolenum perchlorate. 


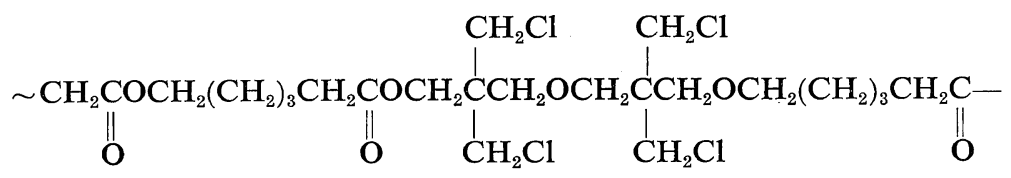
A $\quad \mathbf{F} \quad \mathbf{E}$
$\mathbf{A}^{\prime} \mathbf{C}$ D
D C D
B $\mathbf{F} \quad \mathbf{E}$

Table II. Copolymerization of tetrahydrofuran with $\varepsilon$-caprolactone ${ }^{a}$

\begin{tabular}{cccc}
\hline $\begin{array}{c}\text { CL, mol\% } \\
\text { in monomer } \\
\text { feed }\end{array}$ & $\begin{array}{c}\text { Methanol } \\
\text { insoluble } \\
\text { polymer, wt } \%\end{array}$ & $\begin{array}{c}\text { CL, mol\% in } \\
\text { copolymer }\end{array}$ & $\bar{M}_{n}$ \\
\hline 7.8 & 54.5 & 12.5 & 7410 \\
22.7 & 64.1 & 20.0 & 5170 \\
38.9 & 59.8 & 28.5 & \\
53.3 & 47.2 & 36.5 & 2810 \\
69.3 & 43.2 & 46.0 & 3240 \\
84.1 & 38.2 & 59.1 & \\
100 & 48.4 & 100 & 2680 \\
\hline
\end{tabular}

a $\mathrm{Et}_{3} \mathrm{O} \cdot \mathrm{BF}_{4}, 6.47 \times 10^{-4} \mathrm{~mol} ;$ monomer, $6.5 \times 10^{-2}$ mol; time, $13.5 \mathrm{hr}$; temp, $30^{\circ} \mathrm{C}$; in ethylene dichloride $1 \mathrm{~m} l$.

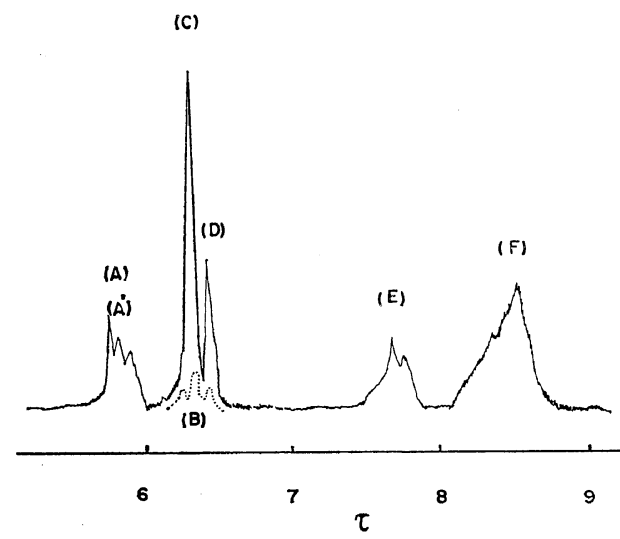

Figure 3. NMR spectrum of a copolymer of 3,3bischloromethyloxetane and $\varepsilon$-caprolactone, polymerized in equimolar monomer feed with 2-methyl1,3-dioxolenium perchlorate.

The decrease of peak $\mathbf{D}$ against peak $\mathbf{C}$ demonstrates the occurrence of cross sequences. Therefore, the formation of the copolymer by the cross propagation reaction may be expected for the present THF-CL system, in which we can not directly detect the cross sequences by NMR. Characterization of the Copolymer of Tetrahydrofuran and $\varepsilon$-Caprolactone

Further studies on the copolymerization be- havior were carried out by using 2,2-octamethylene-bis-1,3-dioxolenium perchlorate as a catalyst. Measurement of the destruction of the cationic living end in the copolymerization system was best accomplished by the ion coupling experiment. In a previous paper, ${ }^{12}$ we concluded that the purity of poly-THF dication reaches more than $98.7 \%$ with this catalyst system from the ion-coupling reaction with $\alpha$ methylstyrene tetramer dicarboxylate-anion. The result of the ion-coupling reaction shown in Table III indicates that the concentration of the cationic living end was $87 \%$. The gel-permeation chromatogram of a copolymer showed tailing at low-molecular-weight region as shown in Figure 4. Fractionation of benzene solution of the copolymer with methanol as a precipitant was attempted as shown in Table IV. The lower-molecular-weight fraction was richer in CL content, which might correspond to the tailing of the GPC diagram. This result might

Table III. Ion coupling of poly(THF-CL) dication and $\alpha$-methylstyrene tetramer dicarboxylate-anion

\section{THF-FCL}

$[\mathrm{THF}]_{0}, 4.27 \times 10^{-1} \mathrm{~mol} ;[\mathrm{CL}]_{0}, 1.011 \times 10^{-1} \mathrm{~mol}$; $[\mathrm{OMDO}]_{0}, 4.02 \times 10^{-4} \mathrm{~mol}$; temp, $0^{\circ} \mathrm{C}$; time, 18 hr; 9.8-\% conversion; $\bar{M}_{n} 7200$. $\mathrm{MS}_{4}$ $4.08 \times 10^{-4} \mathrm{~mol} ; \bar{M}_{n} 560$.

Ion coupling

room temp, $40 \mathrm{hr}$; block copolymer, $4.01 \mathrm{~g} ; \bar{M}_{n}$ 5400 ; room temp, numbers of repeating unit, $n=7.0,\left[(\mathrm{THF}-\mathrm{CL})\left(\mathrm{MS}_{4}\right)\right]_{n}$, per cent of living cation end 87 .

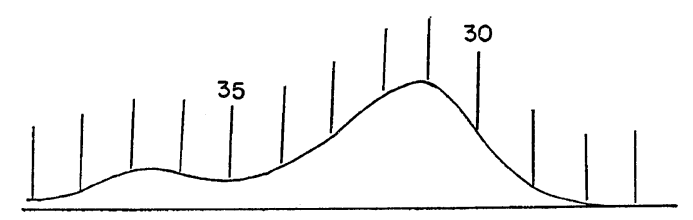

Figure 4. The GPC chromatogram of the THFCL copolymer in THF: $\bar{M}_{n}, 52000 ; \mathrm{CL}, 18.9 \mathrm{~mol} / \%$. 
Table IV. Fractional precipitation of a THFCL copolymer

\begin{tabular}{ccc}
\hline Fraction & $\bar{M}_{n}$ & $\mathrm{CL}, \mathrm{mol} \%$ \\
\hline I & 2000 & 37.0 \\
II & 2700 & 21.3 \\
III & 2600 & 17.6 \\
IV & 2900 & 19.1 \\
\hline
\end{tabular}

be ascribed to the formation of the dead polymer due to termination or chain-transfer reactions of CL. Such a broad distribution of the copolymer composition was unexpected from the apparent random behavior in this copolymerization.

In the IR spectrum of the copolymer film, the crystalline band of poly-THF at $1000 \mathrm{~cm}^{-1}$ disappeared. However, the X-ray diffraction pattern of the copolymer (CL content, 11.2 mol\%) showed strong diffraction at $2 \theta=20^{\circ}$ and $24^{\circ}$ ascribed to the crystalline peak of poly-THF, but no peak appeared at $2 \theta=21.4^{\circ}$ of poly-CL. The thermogram of the copolymer by differential scanning calorimeter also showed an endotherm at the melting point of poly-THF $\left(30 \sim 37^{\circ} \mathrm{C}\right)$, but no peak appeared at $55 \sim 60^{\circ} \mathrm{C}$ of poly-CL. Thus, long crystalline sequences of poly-THF still existed in the copolymer although that of poly-CL vanished. On the other hand, the copolymer richer in CL content (CL, $26.7 \mathrm{~mol} \%$ ) showed a crystalline peak of poly-CL by X-ray diffraction and differential scanning calorimetry at the expense of the crystalline peak of polyTHF. It was therefore concluded that this copolymer has a long sequences of THF and/or CL.

Such phenomena might be explained by the two-state mechanism. ${ }^{13}$ From the sequence distribution of the cationic copolymers of BCMO with $\beta$-propiolactone ${ }^{11}$ and $\gamma$-butyrolactone, ${ }^{13}$ the existence of a coordinated-cationic site besides normal-cationic site was suggested in the poly- merization of lactones. In the present copolymerization system, this mechanism can also explain the existence of both long THF sequences and long $\mathrm{CL}$ sequences in the copolymer.

In conclusion, cationic copolymer of THF and $\mathrm{CL}$ showed a block character in spite of the apparent random kinetic behavior. The complex feature of ionic copolymerization is suggested.

Acknowledgement. Part of this work was supported by the Takeda Science Foundation.

\section{REFERENCES}

1. P. Dreyfuss and M. P. Dreyfuss, Advan. Polym. Sci., 4, 528 (1967).

2. J. M. Hammond, J. F. Hooper, and W. G. P. Robertson, J. Polym. Sci., Part A-1, 9, 265, 281 (1971).

3. T. Saegusa, S. Matsumoto, and Y. Hashimoto, Macromolecules, 3, 377 (1970); ibid., 4, 1 (1971).

4. Y. Yamashita, T. Tsuda, H. Ishida, and M. Hasegawa, Kogyo Kagaku Zasshi (J. Chem. Soc. Japan, Ind. Chem. Sect.), 71, 755 (1968).

5. H. Cherdron, H. Ohse, and F. Korte, Makromol. Chem., 56, 179 (1962).

6. H. Meerwein, J. Pract. Chem., 154, 83 (1939).

7. Y. Yamashita, M. Hirota, H. Matsui, A. Hirao, and K. Nobutoki, Polymer J., 2, 43 (1971).

8. Y. Yamashita, S. Kozawa, M. Hirota, K. Chiba, H. Matsui, A. Hirao, M. Kodama, and K. Ito, Makromol. Chem., 142, 171 (1971).

9) Y. Yamashita, T. Tsuda, M. Okada, and S. Iwatsuki, J. Polym. Sci., Part A-1, 4, 2121 (1966).

10. T. Tsuda, T. Shimizu, and Y. Yamashita, Kogyo Kagaku Zasshi (J. Chem. Soc. Japan, Ind. Chem. Sect.), 67, 2150 (1964).

11. Y. Yamashita, T. Asakura, M. Okada, and K. Ito, Macromolecules, 2, 613 (1969).

12. Y. Yamashita, K. Nobutoki, Y. Nakamura, and M. Hirota, ibid., 4, 548 (1971).

13. K. Ito, T. Inoue, and Y. Yamashita, Makromol. Chem., 139, 153 (1970). 